\title{
Determination of protein and amino acid digestibility in foods including implications of gut microbial amino acid synthesis
}

\author{
Malcolm Fuller* \\ 107 Quaker Path, Stony Brook, NY 11790, USA \\ (Submitted 30 August 2011 - Final revision received 29 November 2011 - Accepted 13 December 2011)
}

\begin{abstract}
To meet the protein and amino acid requirements of individuals and of populations requires information not only about their requirements but also about the capacity of available foods to meet those requirements. Most of our current knowledge of the digestibility of food proteins and the methods to estimate it has been derived from work with animals. Because the microbiota of the large intestine alter the amino acid composition of the digesta, and because only trivial quantities of amino acids are absorbed intact from the large intestine, the current method of choice for assessing amino acid digestibility is ileal digestibility corrected for basal endogenous losses, that is, standardized ileal digestibility. For protein as a whole, however, because nitrogen absorbed in forms other than as amino acids can contribute to the nitrogen economy, the absorption of nitrogen over the whole digestive tract is the more appropriate measure. Most of the methods developed for estimating ileal amino acid outflow in animals are not directly applicable to man: the exception is the use of volunteers with an ileostomy. The flow and composition of ileal digesta in human subjects can also be measured by the infusion of a marker and withdrawal of samples through a naso-intestinal tube. However, this method is too demanding for routine use and is likely to be restricted to validating the application to humans of digestibility data obtained either from animals, of which the pig seems most suitable, or in vitro methods. Microbial activity in the gastrointestinal (GI) tract is not confined to the large intestine: the numbers and metabolic activity of the upper GI microbiota lead to substantial amounts of microbial protein leaving the ileum. It appears however that a large proportion of the amino acids used by the upper GI microbiota are preformed - from the diet or from endogenous materials - rather than from de novo synthesis. Although there are still uncertainties about the impact of microbial activity in the upper GI tract, the amino acid composition of ileal digesta provides the best available basis for estimating the proportion of dietary amino acids available for metabolism.
\end{abstract}

\section{Key words: Protein: Amino acid: Digestion: Fermentation: Microbiota}

To meet the protein and amino acid requirements of individuals and of populations, information is needed not only about those requirements but also about the capacity of available foods to meet them. These two kinds of information have to be expressed in the same terms. As it happens, human amino acid requirements have, for the most part, been investigated using diets based on proteins of high bioavailability such as egg or milk, or on free amino acids, which are assumed to be completely absorbed, or on a mixture of the two. So the estimates of requirements are essentially of the protein and amino acids absorbed, i.e., the metabolic requirements. The compatible information that is required to describe foods is two-fold, comprising the concentration and bioavailability of the protein and amino acids that individual foods or mixed diets contain.

The term bioavailability ${ }^{(1-3)}$ encompasses three properties of foods that can alter the proportion of an amino acid that can be utilized; these properties are digestibility, which describes the net absorption of the amino acid, chemical integrity, which describes the proportion of the amino acid that, if absorbed, is in a utilizable form, and freedom from interference in metabolism resulting from the presence in the food of substances that limit the utilization of the amino acid. Of these, the greatest source of variation in bioavailability is, in most cases, digestibility.

Most of our current knowledge of the digestibility of foods, and of methods to estimate it, has been derived from work with animals. It may therefore be useful to begin by reviewing what has been learned with animals before considering how far those results and those methods may be applied in the context of human nutrition. Although the motivation for obtaining suitable information is different - in commercial animal production efficient use of nutrients is a major determinant of profit - the overall aim of matching food resources most effectively to nutrient needs is the same. In this review the nutrients to be considered are the dietary indispensable amino acids and the total protein. 


\section{Digestibility: amino acids}

The commonly used term "amino acid digestibility" does not of course refer to the degradation of amino acids but is shorthand for the proportion of consumed amino acid that is absorbed.

It is worth emphasizing at the outset that digestibility is not a fixed attribute of a food but reflects an interaction between the food and the person or animal eating it. Of course, the composition of a given food is subject to many sources of variation from one sample to the next, but in a given sample chemical composition can - in theory at least - be determined with high precision. Its digestibility however varies according to how and to whom it is fed, so that the digestibility of a food (or rather of a nutrient within that food) cannot be assigned a unique value relevant to all species or all individuals of a species.

For amino acids the current method of choice is ileal digestibility $^{(3)}$. The road to this consensus has been a long one and this is not the place to rehearse all of the evidence that has led there ${ }^{(3-5)}$ but the reasons for this choice stem from two seminal observations. The first observation ${ }^{(6)}$ was that most faecal nitrogen is in the form of microbial protein. Mason et al. ${ }^{(7)}$ estimated from the faecal excretion of diaminopimelic acid (DAPA) that as much as $90 \%$ of the faecal $\mathrm{N}$ of pigs could be of bacterial origin. Subsequent studies using a variety of microbial markers have confirmed this observation. Consequently, the amino acid composition of faeces tends to be closer to that of microbial protein than to that of undigested food residues, so the amino acid composition of faeces varies little with diet. It was concluded that undigested food residues reaching the large intestine are largely degraded by microbial activity during their relatively long residence, their nitrogen being either absorbed or converted into microbial biomass with an amino acid profile more or less independent of their initial composition.

The second observation was that although nitrogen can be absorbed from the large intestine, there is (except perhaps in neonates) little absorption of intact amino acids. This was first demonstrated by Zebrowska ${ }^{(8)}$, who infused hydrolyzed casein into the caecum of pigs. There was very little increase in faecal nitrogen but some $83-90 \%$ of the infused $\mathrm{N}$ was excreted in the urine with little if any improvement in $\mathrm{N}$ retention, in contrast to the substantial response to an oral casein supplement. Other studies, with infusions of protein or amino acids, have confirmed this $\left(\mathrm{see}^{(9)}\right)$. This means that most of the carbon skeletons of indispensable amino acids entering the large intestine from the ileum are irreversibly lost, either through microbial metabolism or excretion in the faeces, although their nitrogen may be absorbed and used, as will be discussed later. It is worth emphasizing that the appearance of ${ }^{15} \mathrm{~N}$-labeled proteins in the blood after caecal administration of ${ }^{15} \mathrm{~N}$-labeled proteins (e.g. ${ }^{(10)}$ ) is not evidence of the absorption of amino acids: most amino acids in the body can acquire ${ }^{15} \mathrm{~N}$ by transamination, as seen in the extensive ${ }^{15} \mathrm{~N}$ labeling of body protein after giving ${ }^{15} \mathrm{NH}_{4} \mathrm{Cl}$ (e.g. $\left.{ }^{(11,12)}\right)$. The infusion into the caecum of growing pigs of a single indispensable amino acid that was deficient in the diet has been shown to be of little or no benefit ${ }^{(13-15)}$. As pointed out elsewhere ${ }^{(9)}$, with infusion into the caecum of protein, rather than single amino acids, however, there has generally been some positive change in nitrogen retention $^{(8,16,17)}$. Because most of the $\mathrm{N}$ infused into the caecum was absorbed, this may be attributable to the addition of non-specific nitrogen, in the same way that dietary supplements of non-essential $\mathrm{N}$ such as urea or ammonium salts can improve nitrogen balance ${ }^{(18-20)}$. An increased supply of non-amino $\mathrm{N}$ can be expected to increase urea recycling and microbial amino acid synthesis in the small intestine, where the microbial amino acids seem to be mostly absorbed $^{(21)}$, which may be of nutritional benefit ${ }^{(22)}$. Taken together therefore the evidence suggests that most of the carbon skeletons of amino acids entering the large intestine from the ileum are irreversibly lost, either through microbial metabolism or excretion in the faeces, although their nitrogen may be absorbed and used.

In consequence of these observations it is widely agreed that estimates of the amino acids absorbed from the diet would best be derived from measurement of the flow of amino acids leaving the small intestine; that is, ileal digestibility. However, not all the amino acids leaving the ileum are of immediate dietary origin: some are the remnants of endogenous secretions and cellular material: their loss represents part of the requirement and must be deducted from the amino acid flow in order to estimate the contribution of unabsorbed amino acids from the diet. This is the correction of apparent to true digestibility.

For protein as a whole, however, because nitrogen absorbed in forms other than as amino acids can contribute to the nitrogen economy, the absorption of nitrogen over the whole digestive tract is the more appropriate measure. This simply requires the collection and analysis of faeces, which is straightforward; it also requires correction for endogenous losses.

The required measures are therefore of nitrogen and amino acid intakes, of ileal amino acid outflow and of faecal nitrogen loss, together with appropriate values for the endogenous components, which will be considered in more detail in later papers ${ }^{(23,24)}$.

\section{The measurement of ileal amino acid outflow}

Methods for measuring ileal amino acid outflow have been reviewed elsewhere ${ }^{(25-28)}$ and only a brief synopsis will be given here. The methods can be divided into two classes: those in which the whole outflow is collected and those in which only a sample is collected, which is related to the whole flow by use of an indigestible marker. To collect the whole flow requires an ileostomy or ileo-rectal anastomosis and the continuous collection must be sufficiently long for day-to-day variation to be minimized. Whilst obviating the need for a marker, each of these approaches brings its own potential problems. Removal of the ileal digesta means that the potential for recycling nitrogen from the large intestine is lost, with possible consequences for the nitrogen transactions of the small intestine. Although this objection may be 
overcome by returning the digesta to the large intestine after sampling via a second cannula ${ }^{(29)}$, the disturbance of normal gut motility by the transection of the gut may in turn alter the digestive processes. A further concern is that, following an ileostomy or ileo-rectal anastomosis, the microbial population and the morphology of the ileum undergo changes that may alter the nature and extent of digestion there so that they more closely resemble those of the caecum and colon $^{(30,31)}$. This may be more relevant with an ileostomy than with an ileorectal anastomosis as Hennig et $a l^{(32)}$ reported little change with time in ileal microbial numbers during a 5-month period after ileo-rectal anastomosis in pigs. A further and perhaps decisive concern is the welfare of animals with an ileo-rectal anastomosis.

Digesta collection involving indigestible markers allows shorter and simpler procedures. At its simplest, animals can be killed some time after a test meal and the digesta in the terminal ileum can be removed and the concentrations of amino acids and of marker estimated. Although simple, this approach has several practical problems. First, each animal can be used only once, so that variation between animals cannot be reduced as it can by repeated within-animal measurements. Second, especially with small animals, there may be insufficient digesta at the very end of the ileum for the necessary analyses. Collecting digesta from a longer segment of the ileum means that some will be less completely digested.

Commonly used markers include chromic oxide, titanium oxide and acid-insoluble ash. Other heavy metals and rare earth elements have also been used. Dual-phase markers have also been advocated on the premise that amino acids are contained in both liquid and solid phases of the digesta and both need to be represented. Although there have been some comparisons of markers there does not seem to be any consensus as to the relative merits of the various substances.

All methods involving indigestible markers involve the assumption that the marker is distributed in the digesta in the same way as the amino acid (or other nutrient) being measured. This does not necessarily require that the digesta be homogeneous but that the proportion of the intake of marker in the sample be the same as the proportion of the total amino acid flow that is in that sample. This in turn requires the assumption that all the marker fed should reach the point of sampling. Although some investigators have reported virtually complete recovery ${ }^{(36)}$ others have reported recovering significantly less than $100 \%^{(37-39)}$, especially of chromic oxide. Marker recovery may well vary amongst marker substances and methods of preparation and administration but complete recovery of the chosen marker is often not tested.

To collect digesta repeatedly and without interrupting normal digesta flow various cannulas have been developed, the simplest being a T-cannula in the terminal ileum. When the T-branch is opened a variable proportion of the flow is diverted to the outside where it can immediately be chilled until analyzed. For most diets this works well but, especially with fibrous materials, there may be a fractionation of the digesta so that the material exiting the cannula is no longer representative of the whole flow. To overcome this problem a post-valvular cannula has been developed ${ }^{(33,34)}$. This is placed just distal to the ileocaecal junction but so arranged as to divert, while the sample is being collected, practically the whole outflow through the ileo-caecal valve to the exterior. The advantages of this technique now seem to make it the method of choice with pigs. Whatever method is used to obtain digesta it is essential that digesta are collected as soon as they emerge and further bacterial activity prevented: failure to do so results in exaggerated NSP digestibility and presumably other fermentative changes ${ }^{(35)}$.

\section{Apparent, true and standardized ileal digestibility}

Subtracting ileal amino acid outflow from amino acid intake gives apparent digestibility. However, because of the contribution of endogenous amino acids to the ileal outflow - a contribution that is neither constant nor proportional to the protein intake - the value obtained depends on the way the food has been given. In particular, the test protein must be included in the diet above a certain threshold concentration to obtain plateau values of apparent digestibility ${ }^{(40-42)}$. However, to obtain digestibility values for individual foods that can be used additively to predict the digestibility of a complete diet, apparent digestibility values must be corrected appropriately for the endogenous losses. For this purpose endogenous losses are considered as consisting of three components, a basal loss that is independent of the diet and which forms part of the animal's requirement, an additional loss that is induced by giving protein (or peptides, or amino acids) per se (regardless of their source or digestibility) and a further loss which can be accounted as a charge against the particular food, reducing the proportion that is available to meet metabolic requirements. The time-honoured term true digestibility refers to the value corrected for all endogenous losses: the more practical measure is the one corrected only for basal losses, that is, standardized digestibility ${ }^{(3)}$. These issues, as well as endogenous losses and their measurement form the subject of other contributions to this symposium ${ }^{(23,24)}$ and will not be discussed further here.

\section{Measurement of ileal outflow in human subjects}

Clearly, most of the methods used to estimate ileal amino acid flows in animals cannot be considered with human subjects. The exception is the use of volunteers who have an ileostomy. This allowed the first direct comparison between measurements in man and those in animals given the same diets ${ }^{(43)}$. Although, as mentioned above, the physiology and microbiology of the ileum are altered following ileostomy, the quantitative effects of these changes on protein digestion and ileal amino acid outflow are not yet known. For example ${ }^{(43)}$, the ileal digestibility of pectin and hemicellulose in ileostomates was 0.87 and 0.45 and the daily output of DAPA in ileostomy fluid was $31 \mathrm{mg}$, about $40 \%$ of that in faeces, which suggests a distribution of fermentation between the small and large 
intestine similar to that in the pig. However, we do not know what these values would be in intact subjects.

An alternative approach to measuring the flow and composition of ileal digesta in human subjects has been made by the infusion of a marker and withdrawal of samples through a naso-intestinal tube ${ }^{(44)}$. This allowed the digestibility of the same proteins to be compared in pigs and intact human subjects ${ }^{(45)}$. Those comparisons were of purified proteins: the very small diameter of the sampling tube $(1.5 \mathrm{~mm})$ probably limits the application of this approach to such materials, or possibly to very finely ground foods. In any case, this method is too demanding for routine use and is likely to be restricted to validating the application to humans of digestibility data obtained by other means, either another animal species or an in vitro system (e.g., ${ }^{(46,47)}$ ). The approach of Le Gall et al. ${ }^{(48,49)}$, in which the peptide residues of undigested dietary proteins and endogenous proteins in ileal digesta were identified by immuno-blotting and mass spectrometry might also be used to examine the extent of digestion of specific proteins in man.

\section{Surrogates for humans}

The principal candidates for providing digestibility data applicable to man are other animals and in vitro systems. The primary requirement of course is simply that the proposed system should provide digestibility values that are either the same as those obtained in man, or that can be transformed numerically by a consistent formula. However, given the paucity of data obtained with human subjects a more feasible starting point is to set out certain contributory requirements.

(1) The digestive system should be similar to that of man.

(2) The system should accept diets as consumed, and not require additional processing.

(3) Diets should be completely consumed, with no selection.

Animals that are commonly used in digestibility studies are the rat, the chicken and the pig.

The first requisite probably excludes birds, which have a gizzard and do not express lactase activity; they also have a shorter retention time of food in the GIT. It probably also excludes rats unless coprophagy is prevented. In addition, to prevent food selection by rats diets must be finely ground or otherwise processed before feeding; processes that may alter digestibility ${ }^{(50)}$. The digestive system of the pig differs from that of man principally in having a large caecum; however, this is not relevant to ileal digestibility. Pigs do not normally practice coprophagy and, true to their reputation, readily eat unprocessed diets without selection.

\section{Possible limitations of ileal digestibility: the role of the upper intestinal microbiota}

As discussed earlier, the reason for rejecting faeces in favour of ileal digesta as the basis for assessing amino acid digestibility is the modifying effect of the large intestinal microbiota on the amino acid composition of the digesta. The upper digestive tract, however, has its own microbiota. Only since the development of culture-independent methods have the extent and diversity of this population been apparent ${ }^{(51,52)}$. Many of the species have never been cultured and we do not yet have a clear picture of the impact of this population on the nitrogen transactions that are of interest to us in terms of digestion and absorption of amino acids. However, there is evidence that its impact, in pigs at least, is considerable. It was estimated, from the concentration of DAPA in the ileal effluent of pigs, that the microbial biomass leaving the ileum was a quarter of that in the faeces ${ }^{(7)}$. Other estimates in pigs show that up to half the nitrogen leaving the ileum may be in microbial biomass ${ }^{(53-55)}$. Studies of microbial metabolic activity, measured as adenylate energy charge, are as high in the ileum as in the large intestine in pigs ${ }^{(56)}$. Related to this microbial activity, substantial digestion of various non-starch polysaccharides has been shown to occur proximal to the ileo-caecal junction ${ }^{(58-60)}$, providing an energy source for microbial amino acid synthesis. It is important to bear in mind that these observations were made in cannulated animals in which there may have been some modification of the normal microbial population and its environment.

Although there have been several studies of the microbiology of human ileostomy fluid ${ }^{(52,61,62)}$ there is understandably rather little information about the normal human ileal microbiota. Ileal digesta have been reported to contain $10^{7}-10^{8}$ bacteria/mL ${ }^{(63-65)}$, two to three orders of magnitude less than in faeces. More recent analyses ${ }^{(66,67)}$ using nucleic acid-based methods have revealed the diversity of organisms in the ileum, the similarities and differences between ileal and colonic flora, and considerable differences between individuals, but each study included samples from only two or three individuals, taken during surgery or at autopsy. Very recent reports based on ileal digesta sampled by nasointestinal tube provide a clearer picture of the microbiota of the normal ileum ${ }^{(68,69)}$

What are the consequences of this microbial activity on the fate of dietary amino acids (and of amino acids in endogenous proteins that may potentially be reabsorbed)? What is the impact of microbial amino acid synthesis in the upper GI tract on estimates of ileal amino acid digestibility?

The gastrointestinal microbiota can both degrade and synthesize amino acids and, given the heterogeneity of the intra-luminal environment, both may occur simultaneously. When Nesheim \& Carpenter ${ }^{(70)}$ pointed out many years ago that microbial degradation of amino acids in the gut would lead to a spurious over-estimate of digestibility, they were referring to faecal nitrogen but the same is true for ileal amino acid digestibility. Equally, a net synthesis of amino acids by the microbiota would lead to an under-estimate of digestibility. Both possibilities need to be considered.

\section{Amino acid catabolism by the upper intestinal microbiota}

It is technically difficult to account for the nitrogen transactions of the GI microbiota, both because of the very diverse populations that coexist, each with its own activities ${ }^{(71)}$, and because the activities of the microbiota are often confounded with those of the gut tissues. Thus, comparisons of amino acid 
disappearance in the upper GIT (i.e. intake minus ileal outflow) with portal uptake ${ }^{(72)}$ include five components: dietary amino acid absorption, absorption of endogenously secreted amino acids, microbial amino acid metabolism (both degradation and synthesis) and amino acid utilization by enterocytes. These have not yet been satisfactorily disentangled. A further complication to assessing microbial amino acid degradation is that, although luminal ammonia is generated from the amino acids of dietary (or endogenous) proteins, it is also produced by the hydrolysis of urea. Typically, in nonruminants, some $20-30 \%$ of whole-body urea synthesis is recycled through the gut ${ }^{(9)}$ : the ammonia generated is either reabsorbed and returned to the urea pool or utilized by the enteric flora. As noted previously ${ }^{(9)}$ the observation ${ }^{(73)}$ that there is an almost equal return of the carbon and nitrogen moieties of urea to the urea pool, together with evidence of urea synthesis in enterocytes ${ }^{(74)}$ suggests that urea hydrolysis may occur close to the brush border, the ammonia generated constituting a pool different in both size and turnover from that produced in the degradation of amino acids. The proportion of the ammonia generated by urea hydrolysis in the human GI tract that returns to the urea pool has generally been estimated to be $10-25 \%{ }^{(75,76)}$ but one estimate was as high as $70 \%{ }^{(73)}$. Interestingly, the proportion was not affected by protein intake ${ }^{(76)}$ or starvation ${ }^{(75)}$. Taken together, the evidence suggests that, in a healthy human, 30-70mgN.kg ${ }^{-1} \cdot \mathrm{d}^{-1}$ from urea hydrolysis contributes to luminal ammonia. Both urea and ammonia pass from the ileum into the large intestine ${ }^{(55)}$ but urea makes only a small contribution to faecal ammonia $^{(76)}$ or faecal microbial protein ${ }^{(78)}$.

Measurements of ammonia concentration in the ileal digesta of pigs show an increase with dietary protein ${ }^{(79)}$, suggestive of greater microbial degradation of amino acids, but without data on luminal ammonia turnover the microbial flux of amino acid $\mathrm{N}$ to ammonia cannot be estimated from these data.

Other breakdown products of amino acids include a variety of amines, some of which have been measured in the ileal digesta of pigs ${ }^{(80)}$. Again, though, their quantitative significance is hard to assess without data on rates of production. The extent of microbial amino acid degradation in the upper GI tract therefore remains an area of uncertainty.

\section{Amino acid synthesis by the upper intestinal microbiota}

The impact of microbial amino acid synthesis in the upper GI tract on ileal digestibility depends on the origin of the amino acids in the microbial protein leaving the ileum. There is an important distinction between microbial amino acids, meaning simply amino acids that form part of microbial protein, and microbially-synthesized amino acids, i.e., those the microorganisms have formed by de novo synthesis, whether the carbon and nitrogen for these syntheses are derived from the degradation of amino acids (dietary or endogenous) or from non-protein materials and non-amino nitrogen. If the microbiota simply incorporate into their protein preformed amino acids - whether of dietary or endogenous origin - that would otherwise have been absorbed the passage of these amino acids into the large intestine represents a loss just as much as if they were not part of microbial protein. However, it is clear that the microbiota of the small intestine do synthesize amino acids de novo, as evidenced by the incorporation of ${ }^{15} \mathrm{~N}$ from ammonium chloride or urea into lysine (which does not transaminate) and of ${ }^{14} \mathrm{C}$ into indispensable amino acids ${ }^{(81,82)}$. It is also known that these microbiallysynthesized amino acids are absorbed, in both animals and $\operatorname{man}^{(81-88)}$ and may thereby contribute to metabolic requirements ${ }^{(22)}$. However, in the assessment of ileal digestibility, microbially-synthesized amino acids in ileal digesta are treated as if they were undigested dietary amino acids and to that extent introduce an error into the estimate.

There is very little quantitative information on the proportion of microbial amino acids in the upper intestinal microbiota that are synthesized de novo. As suggested previously ${ }^{(4)}$, a tentative estimate can be inferred from the relative ${ }^{15} \mathrm{~N}$ enrichments of microbial amino acids in ileal digesta when subjects were given ${ }^{15} \mathrm{NH}_{4} \mathrm{Cl}^{(12)}$. In the most widespread pathway of microbial lysine synthesis the $\alpha-\mathrm{N}$ of lysine is derived from aspartate, the $\epsilon-\mathrm{N}$ from glutamate. One would therefore expect that microbially-synthesized lysine would have a ${ }^{15} \mathrm{~N}$ enrichment intermediate between those of aspartate and glutamate. However, it was much lower than either, roughly one tenth of the average. In an experiment directly addressing this question ${ }^{(89)}$ the contributions of urea, endogenous protein and dietary protein to microbial valine leaving the ileum of growing pigs were assessed by isotope dilution following 4 -day infusions of $\mathrm{L}-\left[1{ }^{13} \mathrm{C}\right]$ valine (to label endogenous valine) and of $\left[{ }^{15} \mathrm{~N}^{15} \mathrm{~N}\right]$ urea to label valine synthesized de novo and by transamination. These results also suggested that more than $90 \%$ of microbial valine in the ileum was derived from dietary and endogenous proteins, not synthesized de novo. However, these pigs were given a high-protein (19\%) diet and it is not clear whether, with a less adequate protein supply, ammonia would have become a more important source of $\mathrm{N}$ for microbial amino acid synthesis. From this admittedly very limited evidence it appears that a large proportion of the amino acids in the protein of the upper GI microbiota are incorporated directly from the diet or from endogenous materials rather than being synthesized de novo.

Thus there seems to be an important quantitative difference between the upper and lower parts of the GI tract in the impact of microbial activity on amino acid utilization, presumably stemming from differences in the substrates available, in the physiology of the organ, especially its ability to absorb amino acids, in the residence time of the digesta, as well as in the numbers and composition of the resident microbiota. Despite the remaining uncertainties then it seems that the amino acid composition of ileal digesta provides the best available basis for estimating the proportion of dietary amino acids absorbed.

In this regard, the statement in the $\mathrm{FAO} / \mathrm{WHO} / \mathrm{UNU}$ technical report on protein and amino acid requirements ${ }^{(90)}$

“....Furthermore, since according to circumstances the net effect of the amino acid metabolism associated with bacterial biomass can be to either remove from 
or add to amino acids passing through the terminal ileum, ileal digestibility of individual amino acids is unlikely to be a more reliable measure of the systemic availability of dietary protein than faecal digestibility."

seems to overestimate the consequences of ileal microbial activity and undervalue the importance of excluding the far greater impact of the large intestine. It seems more logical to conclude that ileal digestibility, whilst not a perfect measure of net amino acid absorption, nonetheless takes us considerably closer to that ideal than amino acid digestibility over the whole gut.

The strength of these arguments in favour of ileal digestibility has led to the widespread adoption of the system in the feeding of non-ruminant animals and tables of the ileal digestibility of amino acids in a wide range of proteins used in animal feeding have been generated. However, at the present time, comparable data on ileal amino acid digestibility in humans is extremely scarce.

\section{Integrative bioavailability assays}

As mentioned earlier digestibility is not the only determinant of bioavailability, although it is usually the most important. Other factors, such as the chemical availability of individual amino acids, notably lysine (and other amino acids) in heatdamaged proteins, can be estimated separately ${ }^{(91,92)}$. Alternatively, bioavailability may be estimated by one of several bioassays that integrate the several factors that limit the extent to which a dietary amino acid is absorbed and available for metabolism. Using a response that is sensitive to amino acid supply these approaches compare individual foods to pure amino acids, usually in the form of a slope-ratio assay. A suitable response, such as growth rate or body protein accretion $^{(93)}$ or AA oxidation ${ }^{(94)}$, of animals fed the test ingredient is related to the AA intake, and the slope of the regression line is compared with that obtained with the pure amino acid. All diets used in this assay must be first-limiting in this AA, and all dietary levels of the AA need to be below the requirement. It is assumed that the response to graded AA intake levels is linear and determined only by the amino acid in question. However, despite the attractions of a method that integrates all the factors that may limit the utilization of dietary amino acids, the approach has the practical disadvantage that a separate assay is required for each amino acid, using a series of diets in which only that amino acid is limiting. It also tends to confound bioavailability with issues of nutrient imbalance, complicating the interpretation of the results. Furthermore, these assays are laborious and costly and, compared with ileal digestibility measurements, the estimated availability values generally have higher standard errors of determination.

\section{Acknowledgements}

This paper was written solely by the author, who had no conflicts of interest. No specific funding was furnished by any funding agency in the public, commercial or not-for-profit sectors.

\section{References}

1. Lewis AJ \& Bayley HS (1995) Amino acid bioavailability. In Bioavailability of nutrients for animals: amino acids, minerals, and vitamins, pp. 35-65 [CB Ammerman, DH Baker and AJ Lewis, editors].: Academic Press.

2. Fuller MF \& Tomé D (2005) In vivo determination of amino acid bioavailability in humans and model animals. $J A O A C$ Int 88, 923-934.

3. Stein HH, Sève B, Fuller MF, et al. (2007) Invited Review: Amino acid bioavailability and digestibility in pig feed ingredients: Terminology and application. J Anim Sci $\mathbf{8 5}$ $172-180$

4. Fuller M (2003) AA bioavailability-A brief history. In Digestive Physiology in Pigs, pp. 183-198, Proc 9th Intl Symp Vol 1 [RO Ball, editor]. Univ. Alberta, Alberta, Canada.

5. Darragh AJ \& Hodgkinson SM (2000) Quantifying the digestibility of dietary protein. J Nutr 130, 1850S-1856S

6. Mason VC \& Palmer RM (1973) The influence of bacterial activity in the alimentary canal of rats on faecal nitrogen excretion. Acta Agric Scand 23, 141-150.

7. Mason VC, Just A \& Bech-Andersen S (1976) Bacterial activity in the hind-gut of pigs 2. Its influence on the apparent digestibility of nitrogen and amino acids. $Z$ Tierphysiol Tierernahr Futtermittelkd 36, 310-324.

8. Zebrowska T (1973) Digestion and absorption of nitrogenous compounds in the large intestine of pigs. Roczniki Nauk Rolniczych B95-3, 85-90.

9. Fuller MF \& Reeds PJ (1998) Nitrogen cycling in the gut Annu Rev Nutr 18, 385-411.

10. Heine W, Wutzke KD, Richter I, et al. (1987) Evidence for colonic absorption of protein nitrogen in infants. Acta Paediatr Scand 76, 741-744.

11. Patterson BW, Carraro F, Klein S, et al. (1995) Quantification of incorporation of [15N]ammonia into plasma amino acids and urea. Am J Physiol 269, E508-E515.

12. Metges CC, Petzke KJ, El-Khoury AE, et al. (1999) Incorporation of urea and ammonia nitrogen into ileal and fecal microbial proteins and plasma free amino acids in normal men and ileostomates. Am J Clin Nutr 70, 1046-1058.

13. Wünsche J, Hennig U, Meinl M, et al. (1982) [Absorption and utilization of amino acids infused into the cecum of growing pigs. 1. Measurement of N-balance for utilization of lysine and isoleucine; isoleucine requirement for growing pigs]. Arch Tierernabr 32, 337-348.

14. Krawielitzki K, Schadereit R, Zebrowska T, et al. (1984) [Absorption and use of amino acids infused into the cecum of growing pigs. 4. Comparative studies on oral or caecal administration of ${ }^{15} \mathrm{~N}$-lysine and ${ }^{15} \mathrm{~N}$-urea, respectively]. Arch Tierernahr 34, 1-18.

15. Darragh AJ, Cranwell PD \& Moughan PJ (1994) Absorption of lysine and methionine from the proximal colon of the piglet. Br J Nutr 71, 739-752.

16. Zebrowska T (1975) The apparent digestibility of nitrogen and individual amino acids in the large intestine of pigs. Rocz. Nauk Rol 97B, 117-123.

17. Gargallo J \& Zimmerman D (1981) Effect of Casein and Starch Infusion in the Large Intestine on Nitrogen Metabolism of Growing Swine. J Nutr 111, 1390-1396.

18. Swendseid ME, Harris CL \& Tuttle SG (1960) The effect of sources of nonessential nitrogen on nitrogen balance in young adults. J Nutr 71, 105-108.

19. Kies CV \& Fox HM (1978) Urea as a dietary supplement for humans. Adv Exp Med Biol 105, 103-118. 
20. Kofrányi E \& Jekat F (1964) Determination of the biological value of food proteins. IX. Substitution of high-value proteins by non-essential nitrogen. Z Physiol Chem 338, 154-158.

21. Torrallardona D, Harris CI \& Fuller MF (2003) Lysine synthesized by the gastrointestinal microflora of pigs is absorbed, mostly in the small intestine. Am J Physiol Endocrinol Metab 284, E1177-E1180.

22. Raj T, Dileep U, Vaz M, et al. (2008) Intestinal microbial contribution to metabolic leucine input in adult men. J Nutr $\mathbf{1 3 8}$, 2217-2221.

23. Moughan PJ \& Rutherfurd SM (2012) Gut luminal endogenous protein: Implications for the determination of ileal amino acid digestibility in humans. Br J Nutr 108(Suppl 2), S258-S263.

24. Columbus D \& De Lange CFM (2012) Evidence for validity of ileal digestibility coefficients in monogastrics. $\mathrm{Br} J \mathrm{Nutr}$ 108(Suppl 2), S264-S272.

25. Fuller M (1991) Methodologies for the measurement of digestion. in Digestive Physiology in Pigs. In Proc 5th Intl Symp, pp. 273-288 [MWA Verstegen, J Huisman and LA den Hartog, editors]. Wageningen, the Netherlands: Wageningen Academic Publishers.

26. Hodgkinson SM \& Moughan PJ (2000) Amino acids - The collection of ileal digesta and characterization of the endogenous component. In Feed Evaluation. Principles and Practice, pp. 57-76 [PJ Moughan, MWA Verstegen and MI Visser-Reyneveld, editors]. Netherlands: Wageningen Pers.

27. Sauer WC, Fan MZ, Mosenthin R, et al. (2000) Methods for measuring ileal digestibility in pigs. In Farm Animal Metabolism and Nutrition, pp. 279-306 [JPF D'Mello, editor]. Wallingford, UK: CAB International.

28. Moughan PJ (2003) Amino acid availability: aspects of chemical analysis and bioassay methodology. Nutrition Research Reviews 16, 127-141.

29. Darcy B, Laplace JP \& Villiers PA (1980) [Collection of digesta flowing into the large intestine after post-ileocolic valve fistulation: preliminary results]. Reprod Nutr Dev 20, 1197-1202.

30. Gorbach SL, Nahas L, Weinstein L, et al. (1967) Studies of intestinal microflora. IV. The microflora of ileostomy effluent: a unique microbial ecology. Gastroenterology 53, 874-880.

31. Köhler T, Mosenthin R, Verstegen MW, et al. (1992) Effect of ileo-rectal anastomosis and post-valve T-caecum cannulation on growing pigs. 1. Growth performance, N-balance and intestinal adaptation. Br J Nutr 68, 293-303.

32. Hennig U, Metges CC, Berk A, et al. (2004) Relative ileal amino acid flows and microbial counts in intestinal effluents of Goettingen Minipigs and Saddleback pigs are not different. J Anim Sci 82, 1976-1985.

33. Van Leeuwen P, van Kleef DJ, van Kempen GJM, et al. (1991) The post valve T-caecum cannulation technique; an alternative method for chyme collection in pigs. Anim Physiol Anim Nutr 65, 183.

34. van Leeuwen P, van Kleef DJ, van Kempen GJM, et al. (1991) The post valve T-caecum cannulation technique in pigs applied to determine the digestibility of amino acid in maize, groundnut and sunflower meal. J Anim Physiol Anim Nutr 65, 183-193.

35. Canibe N \& Bach Knudsen KE (1997) Digestibility of dried and toasted peas in pigs. 1. Ileal and total tract digestibility of carbohydrates. Anim Feed Sci Technol 64, $293-310$.
36. Fairweather-Tait SJ, Minihane AM, Eagles J, et al. (1997) Rare earth elements as nonabsorbable fecal markers in studies of iron absorption. Am J Clin Nutr 65, 970-976.

37. Köhler T, Huisman J, den Hartog LA, et al. (1990) Comparison of different digesta collection methods to determine the apparent digestibilities of the nutrients at the terminal ileum in pigs. J Sci Food Agric 53, 465.

38. Jagger S, Wiseman J, Cole DJ \& Craigon J (1992) Evaluation of inert markers for the determination of ileal and faecal apparent digestibility values in the pig. Br J Nutr 68 , 729-739.

39. Mroz Z, Bakker GC, Jongbloed AW, et al. (1996) Apparent digestibility of nutrients in diets with different energy density, as estimated by direct and marker methods for pigs with or without ileo-cecal cannulas. J Anim Sci $\mathbf{7 4}$, 403-412.

40. Fan MZ, Sauer WC, Hardin RT, et al. (1994) Determination of apparent ileal amino acid digestibility in pigs: Effect of dietary amino acid level. J Anim Sci 72, 2851-2859.

41. Eklund M, Mosenthin R, Piepho HP, et al. (2008) Effect of dietary crude protein level on basal ileal endogenous losses and standardized ileal digestibilities of crude protein and amino acids in newly weaned pigs. J Anim Physiol Anim Nutr 92, 578-590.

42. Eklund M, Mosenthin R, Piepho HP, et al. (2010) Estimates of dietary threshold levels for crude protein and amino acids to obtain plateau values of apparent ileal crude protein and amino acid digestibilities in newly weaned pigs. Arch Anim Nutr 64, 357-372.

43. Rowan AM, Moughan PJ, Wilson MN, et al. (1994) Comparison of the ileal and faecal digestibility of dietary amino acids in adult humans and evaluation of the pig as a model animal for digestion studies in man. Br J Nutr 71, 29-42.

44. Mahé S, Huneau JF, Marteau P, et al. (1992) Gastroileal nitrogen and electrolyte movements after bovine milk ingestion in humans. Am J Clin Nutr 56, 410-416.

45. Deglaire A, Bos C, Tomé D, et al. (2009) Ileal digestibility of dietary protein in the growing pig and adult human. $\mathrm{BrJ}$ Nutr 102, 1752-1759.

46. Boisen S \& Eggum BO (1991) Critical evaluation of in vitro methods for estimating digestibility in simple-stomach animals. Nutr Res Rev 4, 141-162.

47. McDonough FE, Sarwar G, Steinke FH, et al. (1990) In vitro assay for protein digestibility: interlaboratory study. J Assoc Off Anal Chem 73, 622-625.

48. Le Gall M, Quillien L, Guéguen J, et al. (2005) Identification of dietary and endogenous ileal protein losses in pigs by immunoblotting and mass spectrometry. J Nutr $\mathbf{1 3 5}$, 1215-1222.

49. Le Gall M, Quillien L, Seve B, et al. (2007) Weaned piglets display low gastrointestinal digestion of pea (Pisum sativum L.) lectin and pea albumin 2. J Anim Sci 85, 2972-2981.

50. Lahaye L, Ganier P, Thibault JN, et al. (2004) Technological processes of feed manufacturing affect protein endogenous losses and amino acid availability for body protein deposition in pigs. Anim Feed Sci Technol 113, 141-156.

51. Leser TD, Amenuvor JZ, Jensen TK, et al. (2002) Cultureindependent analysis of gut bacteria: the pig gastrointestinal tract microbiota revisited. Appl Environ Microbiol 68 , 673-690.

52. Booijink CC, El-Aidy S, Rajili-Stojanovi M, et al. (2010) High temporal and inter-individual variation detected in the human ileal microbiota. Environ Microbiol 12, 3213-3227. 
53. Poppe S, Meyer H, Bennke HJ, et al. (1983) Zur Protein- und Aminosaürenverdaulichkeit in verschiedenen Damabschnitten beim Schwein. Arch Tierernäbr 33, 743-748.

54. Hennig U, Schönhusen U \& Souffrant WB (1998) Mikrobielles protein in der ilealen Digesta beim Schwein. Schriftenreibe des FBN Dummerstorf, germany 11, 105-124.

55. Miner-Williams W, Moughan PJ \& Fuller MF (2009) Endogenous components of digesta protein from the terminal ileum of pigs fed a casein-based diet. J Agric Food Chem 57, 2072-2078.

56. Bach Knudsen KE, Jensen BB, Andersen JO, et al. (1991) Gastrointestinal implications in pigs of wheat and oat fractions. 2. Microbial activity in the gastrointestinal tract. Br J Nutr 65, 233-248.

57. Jensen BB \& Jorgensen H (1994) Effect of dietary fiber on microbial activity and microbial gas production in various regions of the gastrointestinal tract of pigs. Appl Environ Microbiol 60, 1897-1904.

58. Millard P \& Chesson A (1984) Modifications to swede (Brassica napus $L$.) anterior to the terminal ileum of pigs: some implications for the analysis of dietary fibre. Br J Nutr $\mathbf{5 2}$, 583-594.

59. Rowan AM, Moughan PJ \& Wilson MN (1992) The flows of deoxyribonucleic acid and diaminopimelic acid and the digestibility of dietary fibre components at the terminal ileum, as indicators of microbial activity in the upper digestive tract of ileostomised pigs. An Feed Sci Tech 36, 129-141.

60. Bach-Knudsen KE \& Canibe N (1997) Digestion of carbohydrates in the small and large intestine of pigs fed on wheat or oat based rolls. In Digestive Physiology in Pigs, pp. 562-566 [J-P Laplace, C Fevrier and A Barbeau, editors]., EAAP Publication No88: INRA France.

61. Ruseler-van-Embden JGH, Kool J, van Lieshout LMC, et al. (1991) Enzymic activity in ileostomy effluent with reference to the characteristic flora. Microb Ecol Health Dis 4, 215-222.

62. Fuller MF, Milne A, Harris CI, et al. (1994) Amino acid losses in ileostomy fluid on a protein-free diet. Am J Clin Nutr 59 , $70-73$.

63. Hao WL \& Lee YK (2004) Microflora of the gastrointestinal tract: a review. Methods Mol Biol 268, 491-502.

64. Tannock GW (1995) Normal Microflora: An Introduction to Microbes Inhabiting the Human Body. London: Chapman and Hall.

65. Tannock GW (2007) What immunologists should know about bacterial communities of the human bowel. Semin Immunol 19, 94-105.

66. Hayashi H, Takahashi R, Nishi T, et al. (2005) Molecular analysis of jejunal, ileal, caecal and recto-sigmoidal human colonic microbiota using $16 \mathrm{~S}$ rRNA gene libraries and terminal restriction fragment length polymorphism. J Med Microbiol 54, 1093-1101.

67. Wang X, Heazlewood SP, Krause DO, et al. (2003) Molecular characterization of the microbial species that colonize human ileal and colonic mucosa by using $16 \mathrm{~S}$ rDNA sequence analysis. J Appl Microbiol 95, 508-520.

68. van den Bogert B, de Vos WM, Zoetendal EG, et al. (2011) Microarray analysis and barcoded pyrosequencing provide consistent microbial profiles depending on the source of human intestinal samples. Appl Environ Microbiol 77(6), 2071-2080.

69. Zoetendal EG, Raes J, van den Bogert B, et al. (2012) The human small intestinal microbiota is driven by rapid uptake and conversion of simple carbohydrates. ISME J. $\mathbf{6}$, $1415-1426$.
70. Nesheim MC \& Carpenter KJ (1967) The digestion of heatdamaged protein. Br J Nutr 21, 399-411.

71. Walker AW, Duncan SH, Harmsen HJ, et al. (2008) The species composition of the human intestinal microbiota differs between particle-associated and liquid phase communities. Environ Microbiol 10, 3275-3283.

72. Darcy-Vrillon B, Souffrant WB, Laplace JP, et al. (1991) Exogenous and endogenous contributions to nitrogen fluxes in the digestive tract of pigs fed a casein diet. II. Ileal and faecal digestibilities and absorption of amino acids. Reprod Nutr Dev 31, 561-573.

73. Long CL, Jeevanandam M \& Kinney JM (1978) Metabolism and recycling of urea in man. Am J Clin Nutr 31, 1367-1382.

74. Wu G (1995) Urea synthesis in enterocytes of developing pigs. Biochem J 312, 717-723.

75. Hibbert JM, Jackson AA \& Persaud C (1995) Urea kinetics: effect of severely restricted dietary intakes on urea hydrolysis. Clin Nutr 14, 242-248.

76. Meakins TS \& Jackson AA (1996) Salvage of exogenous urea nitrogen enhances nitrogen balance in normal men consuming marginally inadequate protein diets. Clin Sci (Lond) $\mathbf{9 0}$, 215-225.

77. Wrong OM, Vince AJ \& Waterlow JC (1985) The contribution of endogenous urea to faecal ammonia in man, determined by $15 \mathrm{~N}$ labelling of plasma urea. Clin Sci (Lond) $\mathbf{6 8}$, 193-199.

78. Mosenthin R, Sauer WC, Henkel H, et al. (1992) Tracer studies of urea kinetics in growing pigs: II. The effect of starch infusion at the distal ileum on urea recycling and bacterial nitrogen excretion. J Anim Sci 70, 3467-3472.

79. Opapeju FO, Krause DO, Payne RL, et al. (2009) Effect of dietary protein level on growth performance, indicators of enteric health, and gastrointestinal microbial ecology of weaned pigs induced with postweaning colibacillosis. J Anim Sci 87, 2635-2643.

80. Piva A, Grilli E, Fabbri L, et al. (2008) Intestinal metabolism of weaned piglets fed a typical United States or European diet with or without supplementation of tributyrin and lactitol. J Anim Sci 86, 2952-2961.

81. Deguchi E, Niiyama M, Kagota K, et al. (1978) Incorporation of ${ }^{15} \mathrm{~N}$ administered to germfree and SPF piglets as ${ }^{15} \mathrm{~N}$-urea into amino acids of hydrolyzed liver and muscle proteins. Jpn J Vet Res 26, 68-73.

82. Torrallardona D, Harris CI \& Fuller MF (2003) Pigs' gastrointestinal microflora provide them with essential amino acids. J Nutr 133, 1127-1131.

83. Deguchi E \& Namioka S (1989) Synthesis ability of amino acids and protein from non-protein nitrogen and role of intestinal flora on this utilization in pigs. Bifidobacteria and Microflora 8, 1-12.

84. Tanaka N, Kubo K, Shiraki K, et al. (1980) A pilot study on protein metabolism in the Papua New Guinea highlanders. J Nut. Sci Vitaminol 26, 247-259.

85. Torrallardona D, Harris CI, Coates ME, et al. (1996) Microbial amino acid synthesis and utilization in rats: incorporation of $15 \mathrm{~N}$ from $15 \mathrm{NH} 4 \mathrm{Cl}$ into lysine in the tissues of germ-free and conventional rats. Br J Nutr 76, 689-700.

86. Torrallardona D, Harris CI \& Fuller MF (1996) Microbial amino acid synthesis and utilization in rats: the role of coprophagy. BrJ Nutr 76, 701-709.

87. Metges CC, El-Khoury AE, Henneman L, et al. (1999) Availability of intestinal microbial lysine for whole body lysine homeostasis in human subjects. Am J Physiol 277 , E597-E607. 
88. Jackson AA, Gibson NR, Bundy R, et al. (2004) Transfer of (15) N from oral lactose-ureide to lysine in normal adults. Int J Food Sci Nutr 55, 455-462.

89. Libao-Mercado AJ, Zhu CL, Cant JP, et al. (2009) Dietary and endogenous amino acids are the main contributors to microbial protein in the upper gut of normally nourished pigs. J Nutr 139, 1088-1094.

90. $\mathrm{FAO} / \mathrm{WHO} / \mathrm{UNU}$ (2007) Protein and amino acid requirements in buman nutrition: report of a joint FAO/WHO/ UNU expert consultation. WHO technical report series; no. 935. Geneva: WHO.
91. Carpenter KJ (1960) The estimation of the available lysine in animal-protein foods. Biochem $J$ 77, 604-610.

92. Moughan PJ \& Rutherfurd SM (2008) Available lysine in foods: a brief historical overview. I AOAC Int 91, 901-906.

93. Batterham ES (1992) Availability and utilization of AA for growing pigs. Nutr. Res. Rev 5, 1-18.

94. Moehn S, Bertolo RF, Pencharz PB, et al. (2005) Development of the indicator amino acid oxidation technique to determine the availability of amino acids from dietary protein in pigs. $J$ Nutr 135, 2866-2870. 